Research article

\title{
Heteroatoms doped porous carbon derived from hydrothermally treated sewage sludge: Structural characterization and environmental application
}

\author{
Tingting Liu ${ }^{\text {a, b }}$, Yi Li ${ }^{\text {c }}$, Nana Peng ${ }^{\text {a, b }}$, Qianqian Lang ${ }^{\text {a, b }}$, Yu Xia ${ }^{\text {a, b }}$, Chao Gai ${ }^{\text {a, b }}$, \\ Qingfu Zheng ${ }^{\mathrm{d}}$, Zhengang Liu ${ }^{\mathrm{a}}$, b, * \\ ${ }^{a}$ Research Center for Eco-Environmental Sciences, Chinese Academy of Sciences, Beijing 100085, China \\ ${ }^{\mathrm{b}}$ University of Chinese Academy of Sciences, Beijing 100049, China \\ c State Key Laboratory of Multiphase Complex Systems, Institute of Process Engineering, Chinese Academy of Sciences, Beijing 100190, China \\ d Analysis and Testing Center, Inner Mongolia University for the Nationalities, Tongliao 028000, China
}

\section{A R T I C L E I N F O}

\section{Article history:}

Received 24 January 2017

Received in revised form

24 March 2017

Accepted 25 March 2017

Available online 29 March 2017

\section{Keywords:}

Sewage sludge

Hydrothermal carbonization

Porous carbon

Dye

Response surface methodology

Heteroatom-doping

\begin{abstract}
A B S T R A C T
The heteroatoms ( $\mathrm{N}$ and $\mathrm{S}$ ) doped porous carbons (HAPCs) were prepared from sewage sludge by hydrothermal carbonization and chemical activation for the first time. The porous structures and surface properties of HAPCs were characterized by multiple techniques including SEM-EDS, TEM, BET, XRD, Raman spectroscopy and Boehm's titration. The resultant materials were showed to be naturally $\mathrm{N}$ and $\mathrm{S}$ dual-doped porous carbons (HAPCs), especially for $\mathrm{HAPC}_{\mathrm{HCl}+\mathrm{HF}}$ obtained by $\mathrm{HCl}-\mathrm{HF}$-washing, which was typical 3D hierarchically porous structure with abundant mesopores as well as big pore diameter. Then the performance of $\mathrm{HAPC}_{\mathrm{HCl}+\mathrm{HF}}$ on $\mathrm{AO} 7$ removal was determined through Response surface methodology. The results showed the adsorption behavior obeyed Langmuir isotherm model and the maximum adsorption capacity was up to $440.53 \mathrm{mg} \mathrm{g}^{-1}$ at $25^{\circ} \mathrm{C}$. Kinetics study revealed that the adsorption followed pseudo second-order kinetic and intra-particle diffusion was the main control step. The high removal rate of $\mathrm{AO} 7$ was ascribed to the unique properties of $\mathrm{HAPC}_{\mathrm{HCl}+\mathrm{HF}}$. The great $\mathrm{V}_{\text {mes }}$ and big pore diameter facilitated the diffusion of $\mathrm{AO} 7$ into the intra surface of particle. Meanwhile, the basic groups and doping of $\mathrm{N}$ and $\mathrm{S}$ made $\mathrm{HAPC}_{\mathrm{HCl}+\mathrm{HF}}$ surface had positive charges, then strong $\pi-\pi$ stacking interaction and electrostatic attraction contributed to the highly effective adsorption. This study indicated hydrothermal carbonization coupled with chemical activation was a cost-effective approach to prepare efficient heteroatoms doped porous carbon from sewage sludge towards azo dye contaminated wastewater treatment.
\end{abstract}

๑) 2017 Elsevier Ltd. All rights reserved.

\section{Introduction}

In China, sewage sludge increases with an average annual rate of $13 \%$ and more than 30 million tons of sewage sludge were generated in 2015. As hazardous heavy metals, pathogens and persistent organic pollutants are embedded in sewage sludge (Yang et al., 2017), traditional disposal approaches are phasing out due to public concerns about second liberation of pollutants, and stricter environment regulation (Zhang et al., 2010). Although thermal utilization techniques including pyrolysis, gasification, and

\footnotetext{
* Corresponding author. Research Center for Eco-Environmental Sciences, Chinese Academy of Sciences, Beijing 100085, China.

E-mail address: zgliu@rcees.ac.cn (Z. Liu).
}

combustion can recover energy from sewage sludge with excellent volume reduction and immobilization of the hazardous matters, they face the challenge of secondary pollutants including $\mathrm{NO}_{x}$, toxic fly ash and some persistent organic contaminants.

Taking advantage of the carbonaceous nature, preparing porous carbons from sewage sludge is believed to be an environmentally benign and sustainable technique. Various carbon materials have been prepared from textile sludge, paper mill sludge and municipal sludge and the BET surface and pore volume are dependent mainly on the inherent carbon content and volatile matters in sewage sludge and the activation conditions (Jaria et al., 2017; Smith et al., 2009). These adsorbents from sludge performed well in removing volatile organic compounds (Hsiu-Mei et al., 2009), dyes (Kacan, 2016; Silva et al., 2016) and heavy metals (Zhang et al., 2005) 
from aqueous solution. Nevertheless, preparing carbon materials entails drying sewage sludge, thus making the preparation expensive.

Recently, nitrogen and sulfur doping in carbon or graphene has been reported to improve surface wettability of carbon materials and boost performance of supercapacitors (Qiu et al., 2013). Nitrogen doping can introduce nitrogenous groups, change the inert $\mathrm{sp}^{2}$ hybridization and result in the enhanced active interactions between the graphene surface and adsorbate (Gai et al., 2016; Li et al., 2017). Using cheap biomass wastes like hair (Qian et al., 2014), fish scale (Liu et al., 2016) and Chlorella (Gai et al., 2016) which naturally contain substantial amount of heteroatoms, heteroatoms doped carbons were prepared and used as dye adsorbent and metal ion adsorbent. Similarly, the microorganisms in sludge are potential $\mathrm{N}$ source for $\mathrm{N}$-doped carbon and heavy metals contained in sludge could act as catalysts for the graphitization of $\mathrm{N}$ doped carbon materials. For example, a N, O-doped porous carbon was prepared from sewage sludge and had a high specific surface area, electrochemical energy storage (Yuan and Dai, 2015). Another $\mathrm{N}$-doped mesocellular graphene foam was prepared from sewage sludge and exhibited highly efficient oxygen reduction reaction (Ye et al., 2015).

Hydrothermal carbonization (HTC) is a novel and low cost thermochemical conversion method which converts biomass feedstock including high moisture biomass into carbon rich and coal-like hydrochar. Compared to the biochar prepared from pyrolysis, efficient hydrolysis and dehydration during HTC bestow the hydrochar with more abundant mesopores and rich oxygencontaining functional groups (Jain et al., 2016; Liu et al., 2010). This makes the hydrochar become potential precursor for porous carbons preparation. With respect to sewage sludge, HTC is applied increasingly as a costless pretreatment to improve dewaterability, anaerobic digestion efficiency and fuel quality (Escala et al., 2013; Laurent et al., 2011). Additionally, sewage sludge is abundant with $\mathrm{N}$ (higher than $3 \mathrm{wt} \%$ ) and S (higher than $1 \mathrm{wt} \%$ ) and previous studies had indicated HTC could change the existing form of $\mathrm{N}$ and $\mathrm{S}$, and more than $50 \%$ of stable nitrogen and sulfur were retained into the hydrochar (Peccia and Westerhoff, 2015; Tian et al., 2013; Wang et al., 2016). Therefore, hydrochar derived from sewage sludge is expected to be a cheap and superior precursor of heteroatoms doped carbon materials.

In the present study, a unique $\mathrm{N}$ and $\mathrm{S}$ dual-doped carbon material was prepared from sewage sludge derived hydrochar for the first time. The morphology, chemical composition and porous properties of the resultant material were systematically characterized by multiple techniques. In addition, its performance on removing acid orange 7 (AO7), an azo dye widely used in textile and paper industries, was evaluated. The primary goal of this study was to develop a cost effective technical route to prepare excellent carbon materials and realize high valued utilization of sewage sludge ultimately.

\section{Experimental section}

\subsection{Materials}

The dewatered raw sludge (RS, moisture content of $81 \%$ ) was collected from a municipal sewage treatment plant in Shandong province. The sludge was hydrothermally treated in a stainless steel autoclave reactor equipped with a thermocouple, a pressure gauge and a stirrer. About $1.5 \mathrm{~kg}$ of raw sludge was loaded into the reactor without any pretreatment and then the reactor was heated up to $220{ }^{\circ} \mathrm{C}$ for $60 \mathrm{~min}$. $\mathrm{N}_{2}$ was introduced into the reactor before heating to create free-oxygen condition. After cooling the reactor down to ambient temperature, the solid product (hydrochar) was separated from mixture product by centrifugation and was dried at $105{ }^{\circ} \mathrm{C}$ for $24 \mathrm{~h}$. The properties of raw sewage sludge and the hydrochar were displayed in Table 1 . The AO7 was obtained from a chemical company (McQueen Chemical Company, Shanghai) and the properties of AO7 were displayed in Table S1 in Supplementary materials.

\subsection{Preparation of porous carbons}

The activation was performed through impregnating the hydrochar particles with $3 \mathrm{M} \mathrm{ZnCl}_{2}$ at a ratio of $1: 2.5(\mathrm{~m} / \mathrm{v})$. A 60 min of ultrasonic treatment guaranteed complete mixing of the hydrochar and $\mathrm{ZnCl}_{2}$. After drying at $80{ }^{\circ} \mathrm{C}$, the solid mixture was ground again and then pyrolyzed at $650{ }^{\circ} \mathrm{C}$ for $1.5 \mathrm{~h}$. A N $\mathrm{N}_{2}$ flow rate of $500 \mathrm{~mL} \mathrm{~min}^{-1}$ was introduced to create an oxygen-free atmosphere and evacuate gaseous emissions during pyrolysis. After pyrolysis, the resultant solid product was grounded and divided into two parts: one part was rinsed with $2 \mathrm{M} \mathrm{HCl}$, the other part was firstly rinsed with $2 \mathrm{M} \mathrm{HCl}$ then further washed with $20 \mathrm{wt} \% \mathrm{HF}$. All the samples were finally washed with distilled water until the $\mathrm{pH}$ was close to 7 and then dried at $105^{\circ} \mathrm{C}$ for $24 \mathrm{~h}$. Then the particles within 100-150 mesh were characterized. For easy of comparison, the porous carbon prepared by $\mathrm{HCl}$ washing and $\mathrm{HCl}-\mathrm{HF}$ washing were labeled as $\mathrm{PC}_{\mathrm{HCl}}$ and $\mathrm{PC}_{\mathrm{HCl}+\mathrm{HF}}$, respectively.

\subsection{Characterization of porous carbons}

The elemental analysis was carried out on Elementar vario EL cube Elemental analyzer. HITACHI JEM-2100 Transmission Electron Microscope (TEM) and HITACHI S-4800 Scanning electron microscope (SEM) coupled with energy dispersive spectroscopy (EDS) were used to investigate the morphology and elemental distribution of the samples. The porous properties were determined by an ASAP Quadrasorb SI-MP Automatic specific surface area and pore physical adsorption analyzer. Prior to $\mathrm{N}_{2}$ sorption, the samples were degassed at $150{ }^{\circ} \mathrm{C}$ for $8 \mathrm{~h}$. The crystalline structures were analyzed by X-ray diffraction (XRD) using an X'Pert PRO MPD (PANalytical). Raman spectra was obtained with a LabRAM HR800 (HORIBA Jobin Yvon). The acidic and basic functional groups on the surface were quantified by Boehm's titration method and a batch experiments were also carried out to determine the zero charge point $\left(\mathrm{pH}_{\mathrm{zpc}}\right)$ (Goertzen et al., 2010). The zeta potentials under different $\mathrm{pH}$ were determined using a zeta potential analyzer (Zetasizer Nano ZS90).

\subsection{Design of AO7 removal experiments by response surface methodology}

Response surface methodology (RSM) is a statistical method used to optimize experimental conditions. A 20 runs of experiment was designed according to Central Composite Design (CCD) to investigate individual and synergetic effect of three independent variables involving initial dye concentration, adsorption temperature and contact time on AO7 removal.

Table 1

Proximate and elemental analysis of RS and hydrochar (dry base).

\begin{tabular}{|c|c|c|c|c|c|c|c|c|}
\hline \multirow[t]{2}{*}{ Material } & $\mathrm{C}$ & $\mathrm{N}$ & $\mathrm{S}$ & $\mathrm{O}^{\mathrm{a}}$ & $\mathrm{Ca}$ & Mg & $\mathrm{Ni}$ & $\mathrm{Fe}$ \\
\hline & \multicolumn{4}{|l|}{ (\%) } & \multicolumn{4}{|c|}{$\left(\mathrm{mg} \mathrm{kg}^{-1}\right)$} \\
\hline RS & 26.70 & 4.00 & 1.23 & 22.05 & 3314 & 6123 & 2078 & 22384 \\
\hline Hydrochar & 23.27 & 2.66 & 1.02 & 13.08 & 4400 & 7782 & 2841 & 30371 \\
\hline $\mathrm{HAPC}_{\mathrm{HCl}}$ & 55.33 & 2.34 & 1.90 & 26.17 & nd & nd & nd & nd \\
\hline $\mathrm{HAPC}_{\mathrm{HCl}+\mathrm{HF}}$ & 65.35 & 2.08 & 1.70 & 4.37 & nd & nd & nd & nd \\
\hline
\end{tabular}

Notes:

a -by difference; nd-not detected. 
The factor levels and experimental runs were present in Tables S2 and S3, respectively. In this study, the adsorbent dosage was fixed at $1.0 \mathrm{~g} \mathrm{~L}^{-1}$ which has been frequently applied in previous studies on AO7 removal (Kousha et al., 2012). The adsorbent was placed into a $100 \mathrm{~mL}$ Erlenmeyer flask, containing $20 \mathrm{~mL}$ of AO7 solution with different dye concentrations $\left(40-360 \mathrm{mg} \mathrm{L}^{-1}\right)$. The mixture was shaked for a pre-set time under desired temperatures and then the solution was filtered by $0.45 \mu \mathrm{m}$ membrane and the residual AO7 concentration was determined using UV-visible spectrophotometer (Shimadzu, UV-2450) at $484 \mathrm{~nm}$. The removal rate of $\mathrm{AO7}$ was calculated by the following equation:

Removal rate $(\%)=\frac{C_{0}-C_{t}}{C_{0}} \times 100 \%$

where $\mathrm{C}_{0}\left(\mathrm{mg} \mathrm{L}^{-1}\right)$ and $\mathrm{C}_{\mathrm{t}}\left(\mathrm{mg} \mathrm{L}^{-1}\right)$ are the initial concentration and the concentration at time $t$, respectively. Control experiments were conducted and excluded the interaction between the filter and AO7.

\section{Results and discussion}

\subsection{Characterization of the porous carbons}

The micro-morphologies of raw sludge, the hydrochar, $\mathrm{PC}_{\mathrm{HCl}}$ and $\mathrm{PC}_{\mathrm{HCl}+\mathrm{HF}}$ were showed in Fig. 1. Compared to smooth surface of RS, rough valleys and numerous coarse particles with diameter varying from $32 \mathrm{~nm}$ to $0.5 \mu \mathrm{m}$ were found on hydrochar surface, which was ascribed to the dehydration and the release of volatile during hydrothermal treatment. The rough surface of the hydrochar provided more activation sites for pore development by chemical activation. The minerals in sludge may have an additional negative contribution to pore structure through the solid-state reactions (Zou et al., 2013). Therefore, additional acid washing has been applied widely to enlarge the pores especially for mesopores by etching out of inorganics. Both $\mathrm{HCl}$ and $\mathrm{HF}$ were introduced in this study. Fig. 1c indicated that many cavity-shaped pores were developed on $\mathrm{PC}_{\mathrm{HCl}}$ surface by $\mathrm{HCl}$ washing. The porous structure was further enhanced by $\mathrm{HF}$ washing, which led to a 3D multiple-pores structure with abundant mesopores for $\mathrm{PC}_{\mathrm{HCl}+\mathrm{HF}}$ (Fig. 1d). This result was further confirmed by the TEM images as shown in Fig. 1e and $\mathrm{f}$, in which the substantial amount of mesopores and channels were clearly seen on the surface of $\mathrm{PC}_{\mathrm{HCl}+\mathrm{HF}}$ compared to $\mathrm{PC}_{\mathrm{HCl}}$.

As shown in Table 1, the hydrochar had high content of N, S and $\mathrm{O}$ (2.66\% for $\mathrm{N}, 1.02 \%$ for $\mathrm{S}$ and $13.08 \%$ for $\mathrm{O})$. As a result, the content of $\mathrm{O}, \mathrm{N}$ and $\mathrm{S}$ in $\mathrm{PC}_{\mathrm{HCl}}$, were $26.17 \%, 2.34 \%$ and $1.90 \%$, respectively. In the case of $\mathrm{PC}_{\mathrm{HCl}+\mathrm{HF}}$, the $\mathrm{N}$ and $\mathrm{S}$ were slightly decreased to $2.08 \%$ and $1.70 \%$, respectively. A more remarkable decrease of $\mathrm{O}$ from $26.17 \%$ to $4.37 \%$ was observed due to the thorough removal of $\mathrm{SiO}_{2}$. In order to investigate these elements distribution within the prepared carbon materials, energy dispersive X-ray (EDX) fluorescence was carried out. As depicted in the element mapping of $\mathrm{N}$ and $\mathrm{S}$ (Fig. 2A and B), they distributed homogeneously on surface of
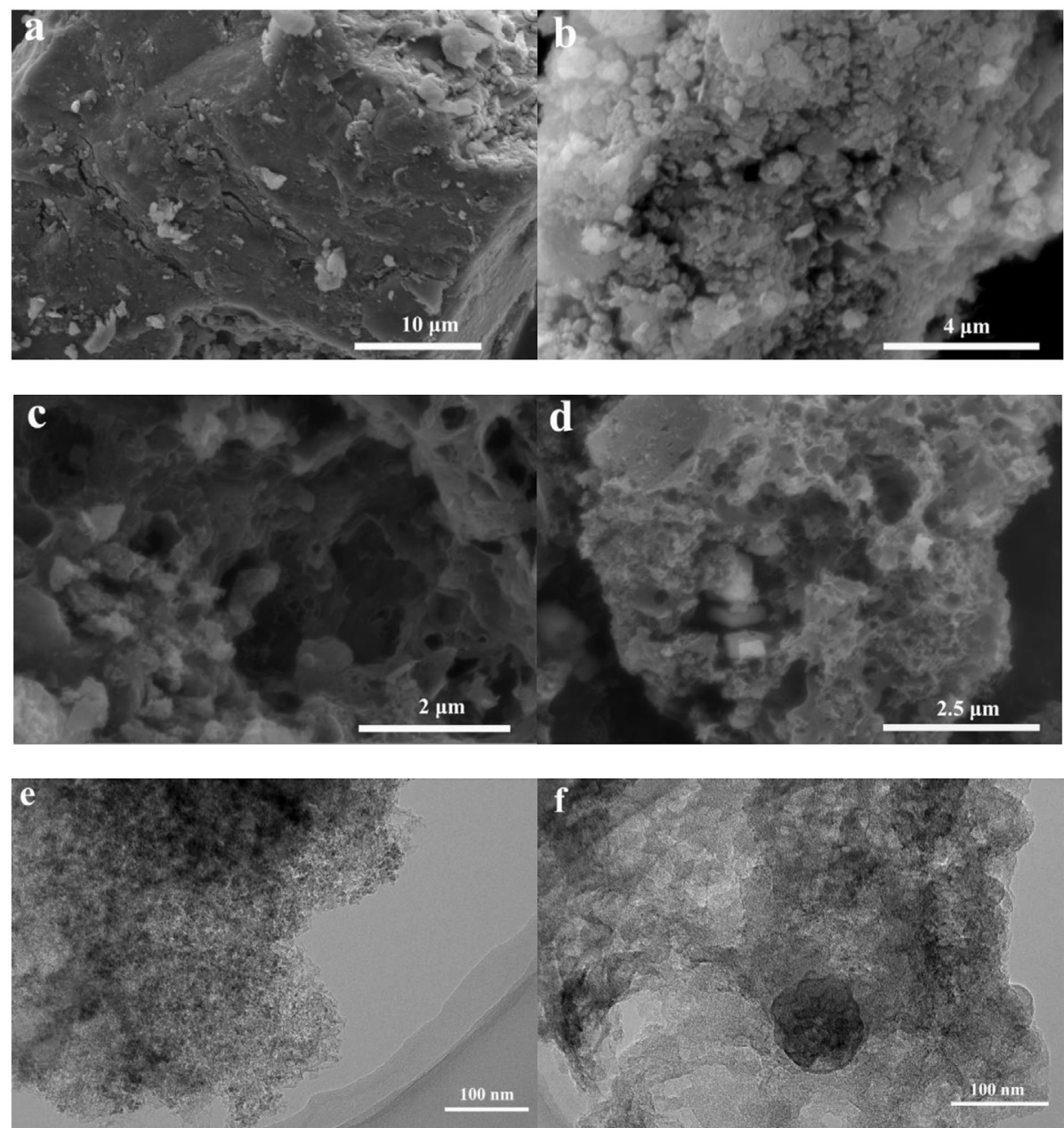

Fig. 1. SEM graphs of raw sludge (a), hydrochar (b), $\mathrm{HAPC}_{\mathrm{HCl}}(\mathrm{c})$ and $\mathrm{HAPC}_{\mathrm{HCl}+\mathrm{HF}}(\mathrm{d})$; $\mathrm{TEM}$ images of $\mathrm{HAPC}_{\mathrm{HCl}}(\mathrm{e})$ and $\mathrm{HAPC} \mathrm{HCl}_{+} \mathrm{HF}(\mathrm{f})$. 

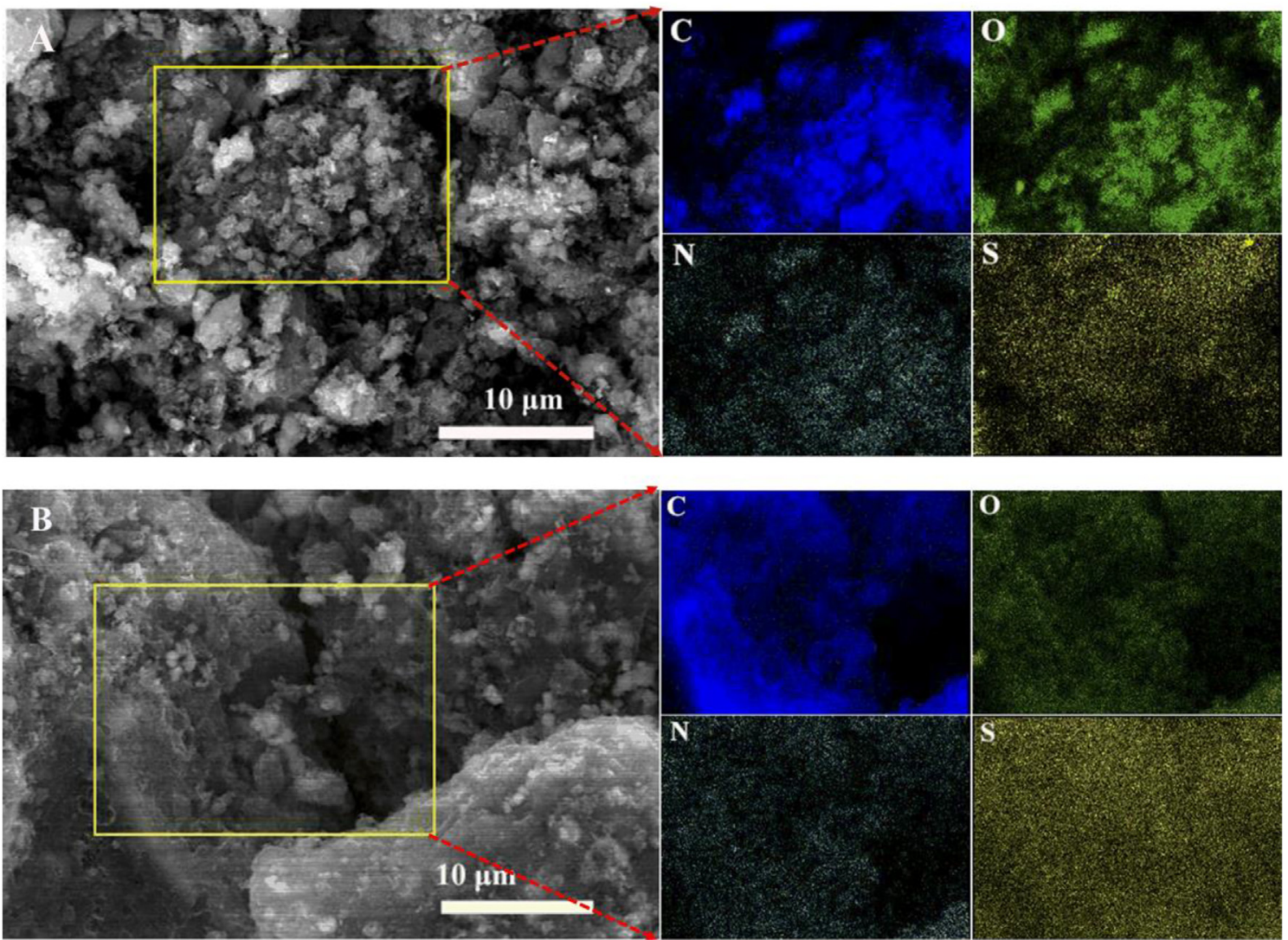

Fig. 2. Element mapping graphs of $\mathrm{HAPC}_{\mathrm{HCl}}(\mathrm{A})$ and $\mathrm{HAPC}_{\mathrm{HCl}+\mathrm{HF}}(\mathrm{B})$.

$\mathrm{PC}_{\mathrm{HCl}}$ and $\mathrm{PC}_{\mathrm{HCl}+\mathrm{HF}}$, respectively, indicating the $\mathrm{PC}_{\mathrm{HCl}}$ and $\mathrm{PC}_{\mathrm{HCl}+\mathrm{HF}}$ were typical heteroatoms ( $\mathrm{N}$ and $\mathrm{S}$ ) doped porous carbons (HAPCs).

Fig. 3A showed XRD patterns of the prepared carbons. Clearly, most impurities were removed by $\mathrm{HCl}$ washing except for $\mathrm{SiO}_{2}$ which showed strong characteristic peaks at $20.8^{\circ}, 26.7^{\circ}$ and $36.6^{\circ}$, and weak peaks at $50.1^{\circ}, 54.8^{\circ}, 60.0^{\circ}$ and $68.3^{\circ}$. It should be noted that $\mathrm{HAPC}_{\mathrm{HCl}}$ possessed a well-developed graphitic structure indicated by the peaks at $22.5^{\circ}$ and $45.8^{\circ}$, and a stacking peak at $26.5^{\circ}$. Compared to $\mathrm{HAPC}_{\mathrm{HCl}}$, XRD pattern of $\mathrm{HAPC}_{\mathrm{HCl}+\mathrm{HF}}$ showed no significant diffraction of $\mathrm{SiO}_{2}$ indicating nearly all $\mathrm{SiO}_{2}$ had been etched out by HF washing. The diffraction peak at $47.16^{\circ}$ was attributed to residual insoluble metal phosphate or calcium fluoride. In addition, a peak at $26.5^{\circ}$ suggested the graphitic structure of $\mathrm{HAPC}_{\mathrm{HCl}+\mathrm{HF}}$ and this was confirmed by the Raman spectra shown in Fig. 3B. The peaks located at around $1340 \mathrm{~cm}^{-1}$ and $1594 \mathrm{~cm}^{-1}$ are assigned to the characteristic D (defects and disorder) and $G$ (graphitic) bands of carbon materials, respectively. The $D / G$ ratio of band intensities indicates the degree of structural order with regarding to a graphitic structure. The $\mathrm{D} / \mathrm{G}$ ratio of 0.85 for $\mathrm{HAPC}_{\mathrm{HCl}+\mathrm{HF}}$ indicated the high graphitization degree. This observation was consistent with XRD result. The considerable graphitic structure of $\mathrm{HAPC}_{\mathrm{HCl}}$ and $\mathrm{HAPC}_{\mathrm{HCl}+\mathrm{HF}}$ was ascribed to the catalytic transformation of amorphous carbon to graphite by inherent $\mathrm{Fe}$ and $\mathrm{Ni}$ in the hydrochar (Table 1) (Yuan and Dai, 2015). In addition, the D peak implied the defects from the ideal graphitic lattice and this might be caused by the heteroatom doping effects (Yuan and Dai, 2015).

To estimate the special surface area and pore size distribution, the BrunauerEmmett-Teller (BET) model and the Barrett-JoynerHalenda (BJH) method were applied to $\mathrm{N}_{2}$ adsorption-desorption date (Liu et al., 2016). Fig. 4 showed both $\mathrm{HAPC}_{\mathrm{HCl}}$ and
$\mathrm{HAPC}_{\mathrm{HCl}+\mathrm{HF}}$ displayed IV curve, which was typical feature of mesoporous solids according to the IUPAC. The isotherms had upward at relative low pressure $\left(\mathrm{P} / \mathrm{P}_{0}<0.4\right)$, demonstrating the presence of

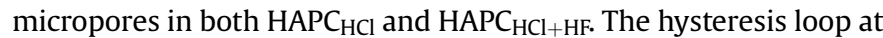
$\mathrm{P} / \mathrm{P}_{0}>0.4$ implied the existence of abundant mesopores. A H4 hysteresis loop for $\mathrm{HAPC}_{\mathrm{HCl}}$ indicated the lamellar pore. In addition, the pore size distribution demonstrated the $\mathrm{HAPC}_{\mathrm{HC}+\mathrm{HF}}$ had larger average pore diameter than $\mathrm{HAPC}_{\mathrm{HCl}}\left(3.7 \mathrm{~nm}\right.$ for $\mathrm{HAPC}_{\mathrm{HCl}}, 4.8 \mathrm{~nm}$ for $\left.\mathrm{HAPC}_{\mathrm{HC}+\mathrm{HF}}\right)$. Additionally, the mesopores volume $\left(\mathrm{V}_{\text {meso }}\right)$ was $0.2 \mathrm{~cm}^{3} \mathrm{~g}^{-1}$ and $0.39 \mathrm{~cm}^{3} \mathrm{~g}^{-1}$ and the total pore volume $\left(\mathrm{V}_{\text {tot }}\right)$ was $0.38 \mathrm{~cm}^{3} \mathrm{~g}^{-1}$ and $0.59 \mathrm{~cm}^{3} \mathrm{~g}^{-1}$, respectively. The highly developed porous structure of $\mathrm{HAPC}_{\mathrm{HC}+\mathrm{HF}}$ compared to $\mathrm{HAPC}_{\mathrm{HCl}}$ was ascribed to the removal $\mathrm{SiO}_{2}$ by HF washing. Consequently, the BET special surface area increased from $417 \mathrm{~m}^{2} \mathrm{~g}^{-1}$ of $\mathrm{HAPC}_{\mathrm{HCl}}$ to $519 \mathrm{~m}^{2} \mathrm{~g}^{-1}$ of

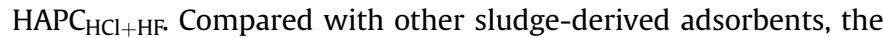
$\mathrm{HAPC}_{\mathrm{HCl}}$ and $\mathrm{HAPC}_{\mathrm{HCl}+\mathrm{HF}}$ had large pore diameters and $\mathrm{V}_{\text {meso }}$ (Lin et al., 2012; Zhang et al., 2005). This observation suggested that HTC combined with chemical activation was an efficient method to elevate mesoporous structure and enlarge pore diameter of carbon materials.

The acidic and basic surface groups of the adsorbent influence significantly on the adsorption properties, therefore, the acidic and basic surface groups of $\mathrm{HAPC}_{\mathrm{HCl}}$ and $\mathrm{HAPC}_{\mathrm{HCl}+\mathrm{HF}}$ were determined and the results were shown in Table 2. The acidic groups including carboxylic groups, lactone groups, phenolic groups and carbonyl groups were 0.54 mequiv $\mathrm{g}^{-1}$ and 0.49 mequiv $\mathrm{g}^{-1}$ for $\mathrm{HAPC}_{\mathrm{HCl}}$ and $\mathrm{HAPC}_{\mathrm{HCl}+\mathrm{HF}}$, respectively. The basic group was 0.22 mequiv $^{-1}$ for

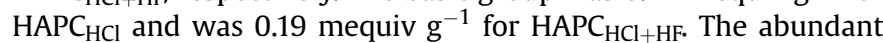
acidic groups were mainly originated from the HTC treatment which bestowed oxygen-containing functional groups on hydrochar surface and most stable oxygen containing groups were 

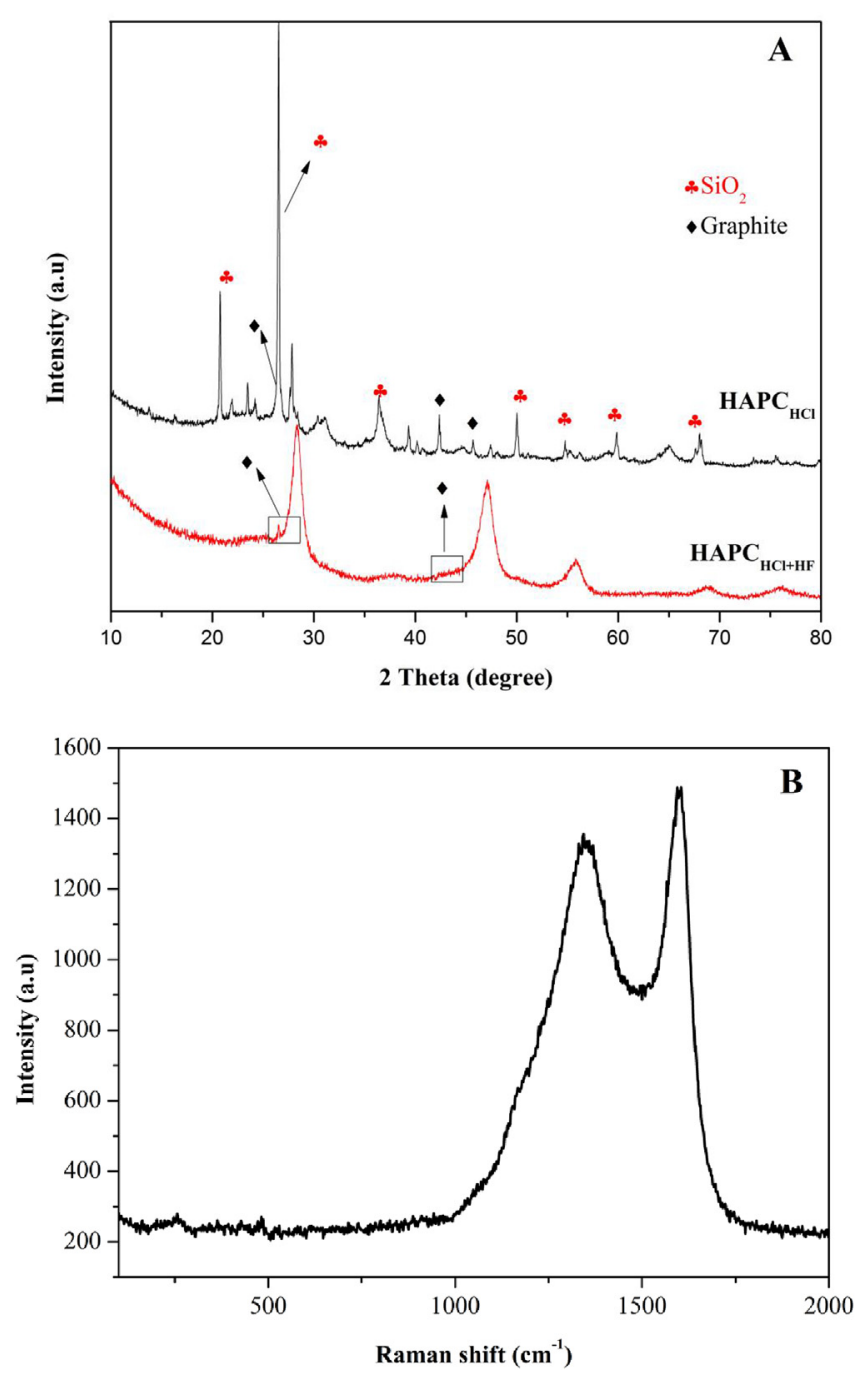

Fig. 3. XRD pattern (A) and Raman spectrum (B) of HAPC.

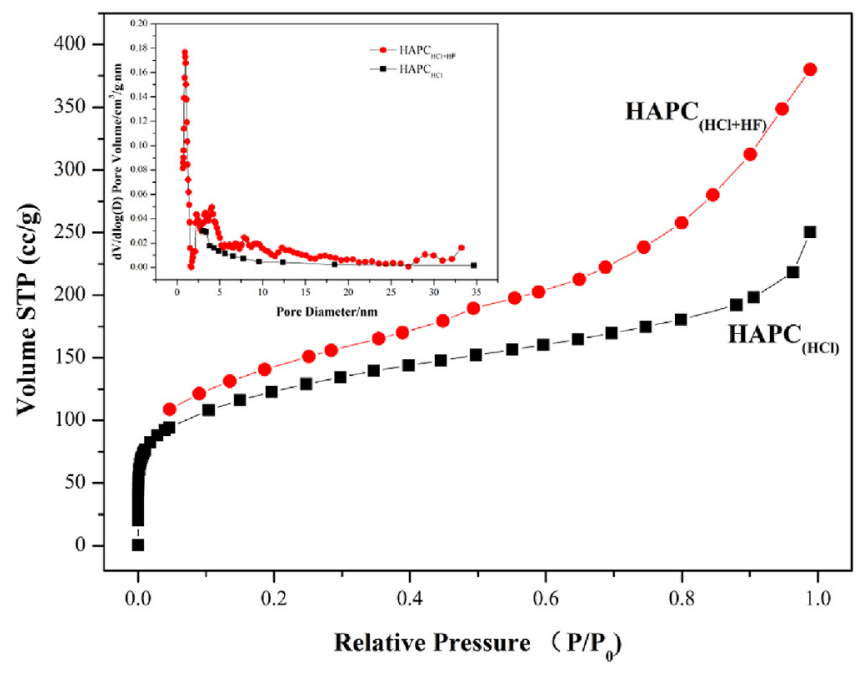

Fig. 4. $\mathrm{N}_{2}$ adsorption-desorption isotherms and pore size distributions of HAPC.

retained during pyrolysis. As for the basic groups, they were ascribed to the pyridine-like structures in the adsorbent (Rio et al.,
2005).

The zeta potentials of HAPC under different $\mathrm{pH}$ were determined (shown in Fig. S1). The potential of $\mathrm{HAPC}_{\mathrm{HCl}+\mathrm{HF}}$ was positive at $\mathrm{pH}<6.5$. This indicated $\mathrm{HAPC}_{\mathrm{HCl}+\mathrm{HF}}$ had high potential to adsorb negatively charged dyes via electrostatic attraction when $\mathrm{pH}$ was lower than 6.5 (Plank and Hirsch, 2007). As for $\mathrm{HAPC}_{\mathrm{HCl}}$, the zeta potential was negative in the $\mathrm{pH}$ range of $2.5-11.0$ and was unfavorable for the adsorption of negatively charged dyes.

\subsection{Adsorption of $A O 7$ onto $H A P C_{H C l+H F}$}

Considering excellent porous properties of $\mathrm{HAPC}_{\mathrm{HCl}+\mathrm{HF}}$, it was adopted to remove dye from aqueous solution.

\subsubsection{Optimization of AO7 adsorption by RSM}

CCD combined with analysis of variance was used to predict the effect of variables and interaction between independent variables on the adsorption for dye. The actual results and predicted values by Design Expert 9.0 were showed in Table S3. It can be seen that the AO7 removal efficiency ranged from $77 \%$ to $100 \%$ under the preset conditions. The results could be fitted to a second-order polynomial regression equation, which was expressed as the following equation:

$y=b+\sum_{i=1}^{k} b_{i} x_{i}+\sum_{i=1}^{k} b_{i i} x_{i}^{2}+\sum_{i=1}^{k-1} \sum_{j=i+1}^{k} b_{i i} x_{i} x_{j}$

where $y$ is the predicted response variable; $b_{0}$ is the constant coefficient; $b_{i}$ is the linear coefficients; $b_{i i}$ is the quadratic coefficients; $b_{i i}$ is the linear coefficients for the interaction between independent variables $\mathrm{i}$ and $\mathrm{j} ; \mathrm{x}_{\mathrm{i}}$ and $\mathrm{x}_{\mathrm{j}}$ are the coded independent parameters. Table S3 displayed the code forms of the independent parameters and corresponding actual, and a final second order polynomial equation which related the adsorption of AO7 to the coded factors were given as bellow:

Dye adsorption $(\mathrm{y})=98.37+1.95 \mathrm{x}_{1}-5.35 \mathrm{x}_{2}+1.28 \mathrm{x}_{3}+1.97 \mathrm{x}_{1} \mathrm{x}_{2}-$ $0.25 \mathrm{x}_{1} \mathrm{x}_{3}+1.38 \mathrm{x}_{2} \mathrm{x}_{3}-0.72 \mathrm{x}_{1}^{2}-2.45 \mathrm{x}_{2}^{2}-0.23 \mathrm{x}_{3}^{2}$

In addition, the small discrepancy (between $-1.04 \%$ and $1.06 \%$ ) between the predicted values and actual values suggested this equation predicted well AO7 adsorption in terms of tested variables.

The analysis of variance for adequacy and statistical significance of the regression coefficient quadratic model for AO7 removal by $\mathrm{HAPC}_{\mathrm{HCl}+\mathrm{HF}}$ was presented in Table S4. The mean squares in the ANOVA were obtained by dividing the sum of the squares of each of variation sources, the model and the error variance by the respective degrees of freedom. The fishers test, F-value (119.23) and Prob $>\mathrm{F}(<0.0001)$ for adsorption of AO7 proved this quadratic model was significant, and there was only a $0.01 \%$ chance that a large F-value could occur due to noise. The determination coefficient $\left(R^{2}=0.9908\right)$ indicated that only $1 \%$ of the total variation could not be explained by the model. Values of Prob $>$ F less than 0.0500 indicates model terms are significant, greater than 0.1000 indicates the model terms are not significant. In this case, $x_{1}, x_{2}, x_{3}$, $\mathrm{x}_{1} \mathrm{x}_{2}, \mathrm{x}_{2} \mathrm{x}_{3}, \mathrm{x}_{1}^{2}, \mathrm{x}_{2}^{2}$ were significant model terms, suggesting temperature, initial concentration and contact time imposed either individually or by way of interactions on the AO7 removal by $\mathrm{HAPC}_{\mathrm{HCl}+\mathrm{HF}}$. The initial concentration was the most effective factor amongst these factors because of the greatest F-value, so as interaction between initial concentration and temperature and contact time were important. In order to deepen the comprehending of effects of their interaction on adsorption, the visualized effects 
Table 2

Textual characteristics of the HAPCs.

\begin{tabular}{|c|c|c|c|c|c|c|c|}
\hline Sample & $\mathrm{S}_{\mathrm{BET}}\left(\mathrm{m}^{2} \mathrm{~g}^{-1}\right)$ & $V_{\text {tot }}\left(\mathrm{cm}^{3} \mathrm{~g}^{-1}\right)$ & $\mathrm{V}_{\text {meso }}\left(\mathrm{cm}^{3} \mathrm{~g}^{-1}\right)$ & Average pore diameter $(\mathrm{nm})$ & Acidic groups (mequiv $\mathrm{g}^{-1}$ ) & Basic groups (mequiv $\mathrm{g}^{-1}$ ) & $\mathrm{pHzpc}$ \\
\hline $\mathrm{HAPC}_{\mathrm{HCl}}$ & 417 & 0.384 & 0.202 & 3.70 & 0.56 & 0.22 & 4.33 \\
\hline $\mathrm{HAPC}_{\mathrm{HCl}+\mathrm{HF}}$ & 519 & 0.588 & 0.387 & 4.83 & 0.49 & 0.19 & 6.40 \\
\hline
\end{tabular}

were obtained by three-dimensional (3D) response surface plots based on the experimental quadratic model.

The effects of temperature and initial dye concentration on adsorption at a fixed contact time at zero level $(t=14 \mathrm{~min})$ were displayed in Fig. 5A. It can be seen that when initial concentration was less than $160 \mathrm{mg} \mathrm{L}^{-1}$, the removal rate increased first and then decreased with increasing temperature. In the concentration range of $160-320 \mathrm{mg} \mathrm{L}^{-1}$, removal rate increased with increasing temperature. When the temperature was below $20^{\circ} \mathrm{C}$, the removal rate increased with the increase of initial concentration. However, when the temperature was higher than $20^{\circ} \mathrm{C}$, removal rate increased initially and then underwent a decrease with increasing initial
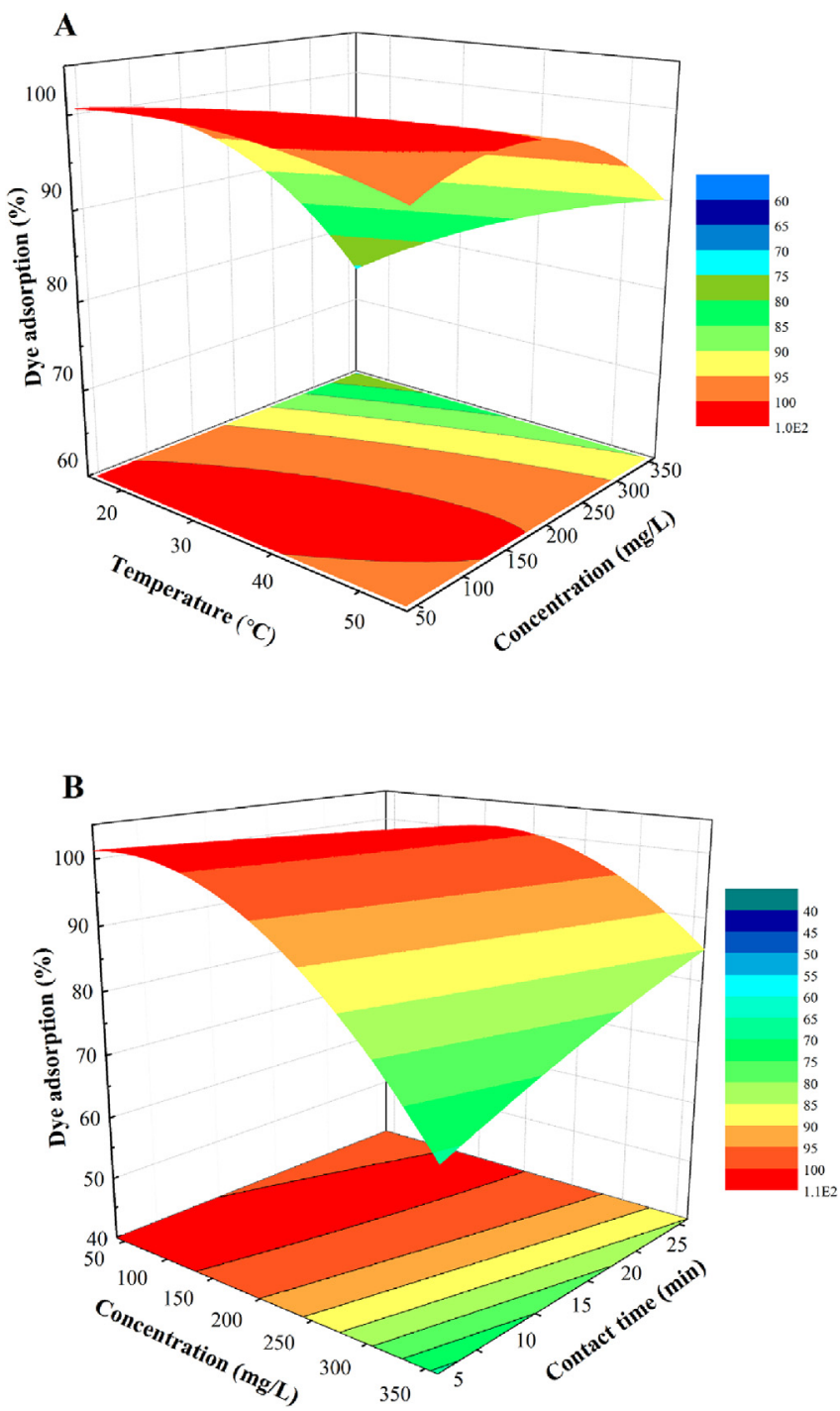

Fig. 5. (A) Three-dimensional response surface plot for effects of initial concentration and temperature on $\mathrm{AO} 7$ removal by $\mathrm{HAPC}_{\mathrm{HCl}+\mathrm{HF}}$ (contact time of $14 \mathrm{~min}$ ); (B) Threedimensional response surface plot for effects of initial concentration and contact time on $\mathrm{AO} 7$ removal by $\mathrm{HAPC}_{\mathrm{HCl}+\mathrm{HF}}$ (temperature at $35^{\circ} \mathrm{C}$ ). concentration. Although increasing temperature was expected to promote adsorption as $\mathrm{AO} 7$ adsorption on carbon materials was endothermic reaction (Elizalde-Gonzalez and Hernandez-Montoya, 2009), increasing temperature only promoted the adsorption at high concentrations, whereas restricted the adsorption of low concentrations in this study.

The interaction between concentration and contact time on $\mathrm{AO7}$ adsorption were depicted in Fig. 5B. At a fixed temperature of $35^{\circ} \mathrm{C}$, the effects of initial concentration of dye on AO7 removal changed with contact time. When contact time was less than 5 min, removal rate decreased obviously with increasing initial concentration, whereas when the contact time ranged from $5 \mathrm{~min}$ to $22 \mathrm{~min}$, the removal rate increased first and then decreased with concentration increasing. It was also observed that prolonging contact time lowered the removal rate at the concentration lower than $150 \mathrm{mg} \mathrm{L}^{-1}$, but increased the removal rate at the concentration higher than $150 \mathrm{mg} \mathrm{L}^{-1}$. Similar observation had been reported in a previous study in which AO7 removal increased with increasing contact time when concentration was higher than $300 \mathrm{mg} \mathrm{L}^{-1}$, while increased first and then decreased with extending contact time when concentration was lower than $300 \mathrm{mg} \mathrm{L}^{-1}$ (Silva et al., 2004).

\subsubsection{Adsorption kinetic}

In this study, the pseudo first-order and pseudo second-order kinetic model were applied to the adsorption of $\mathrm{AO} 7$ on

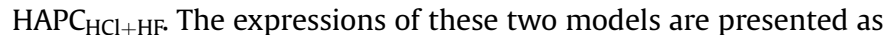
bellow:

$\ln \left(\mathrm{q}_{\mathrm{e}}-\mathrm{q}_{\mathrm{t}}\right)=\ln \mathrm{q}_{\mathrm{e}}-\mathrm{k}_{1} \mathrm{t}$

$\frac{\mathrm{t}}{\mathrm{q}_{\mathrm{t}}}=\frac{1}{\mathrm{k}_{2} \mathrm{q}_{\mathrm{e}}^{2}}+\frac{1}{\mathrm{q}_{\mathrm{e}}} \mathrm{t}$

where $\mathrm{k}_{1}$ and $\mathrm{k}_{2}$ are the first-order rate constant $\left(1 \mathrm{~min}^{-1}\right)$ and the second-order rate constant $\left(\mathrm{g} \mathrm{mg}^{-1} \mathrm{~min}^{-1}\right)$, respectively.

The fitting results of experimental date obtained were showed in Fig. S2 and Table 3. It can be seen the correlation coefficient $\left(\mathrm{R}^{2}\right)$ was close to 1 for different initial concentrations of AO7 solution (120 $\mathrm{mg} \mathrm{L}^{-1}$ and $200 \mathrm{mg} \mathrm{L}^{-1}$ ) and the calculated $\mathrm{q}_{\mathrm{e}}$ values ( $131.75 \mathrm{mg} \mathrm{g}^{-1}$ and $225.70 \mathrm{mg} \mathrm{g}^{-1}$ ) were very close to the experiment results when using second-order kinetic model. In contrast, $\mathrm{R}^{2}$ values of the pseudo-first order model was much low and the calculated $\mathrm{q}_{\mathrm{e}}$ values (19.69 $\mathrm{mg} \mathrm{g}^{-1}$ and $59.62 \mathrm{mg} \mathrm{g}^{-1}$ ) were far lower than experiment results, indicating the second-order kinetic model was the best model for this adsorption. This result implied that adsorption process was controlled by chemisorption including electron sharing or electron transfer between adsorbent and adsorbate and the heterogeneous adsorption sites on $\mathrm{HAPC}_{\mathrm{HCl}+\mathrm{HF}}$ surface were not infinite.

In general, the dye adsorption occurs through three consecutive steps: (1) the surface diffusion stage (inter-particle diffusion or boundary layer diffusion); (2) the intra-particle diffusion, which is the diffusion of dyes into micropores (intra-particle diffusion) and (3) the diffusion of the adsorbate molecules to interior surface and site of adsorbent either by a pore diffusion process through the liquid filled pores or by a solid surface diffusion mechanism, in 
Table 3

Kinetic models Intra-particle diffusion model for AO7 adsorption.

\begin{tabular}{|c|c|c|c|c|c|c|c|c|c|c|c|c|}
\hline \multirow[t]{2}{*}{ Concentration $\left(\mathrm{mg} \mathrm{L}^{-1}\right)$} & \multicolumn{3}{|c|}{ Pseudo first-order } & \multicolumn{3}{|c|}{ Pseudo second-order } & \multicolumn{6}{|c|}{ Intra-particle diffusion } \\
\hline & $\mathrm{qe}_{\mathrm{e}}$ & $\mathrm{k}_{1}$ & $\mathrm{R}^{2}$ & $\mathrm{q}_{\mathrm{e}}$ & $\mathrm{k}_{2}$ & $\mathrm{R}^{2}$ & $\mathrm{k}_{\mathrm{id} 1}$ & $\mathrm{R}^{2}$ & $\mathrm{k}_{\mathrm{id} 2}$ & $\mathrm{R}^{2}$ & $\mathrm{k}_{\mathrm{id} 3}$ & $\mathrm{R}^{2}$ \\
\hline 120 & 19.69 & 0.3700 & 0.9412 & 131.75 & 0.0439 & 0.9999 & 37.14 & 0.9787 & 10.83 & 0.9282 & 0.0715 & 0.9943 \\
\hline 200 & 59.62 & 0.1500 & 0.9261 & 225.70 & 0.0079 & 0.9998 & 44.22 & 0.9704 & 17.43 & 0.9929 & 0.7867 & 0.9016 \\
\hline
\end{tabular}

which inter-particle diffusion and intra-particle diffusion are the main adsorption limited process (Ma et al., 2014). To investigate the diffusion mechanism, the adsorption data was fitted with intraparticle diffusion model which can be expressed as bellow:

$\mathrm{q}_{\mathrm{t}}=\mathrm{k}_{\mathrm{id}} \mathrm{t}^{1 / 2}+\mathrm{C}$

where $\mathrm{k}_{\mathrm{id}}\left(\mathrm{mg} \mathrm{g}^{-1} \min ^{1 / 2}\right)$ is the diffusion constant and $\mathrm{C}$ is a

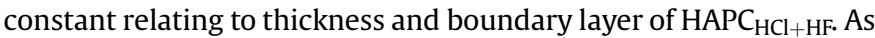
seen from Fig. S3, the plot of $q_{t}$ versus $t^{1 / 2}$ could be divided into three stages. As both straight lines at the first and second stage didn't pass through the origin, the intra-particle diffusion was not the sole rate-limiting step in the adsorption process. While according to Table 4 , the rate constant $\mathrm{k}_{\mathrm{id} 1}\left(37.14 \mathrm{mg} \mathrm{g}^{-1} \mathrm{~min}^{1 / 2}\right.$ and $\left.44.22 \mathrm{mg} \mathrm{g}^{-1} \min ^{1 / 2}\right)$ was much higher than $\mathrm{k}_{\mathrm{id} 2}\left(10.83 \mathrm{mg} \mathrm{g}^{-1}\right.$ $\min ^{1 / 2}$ and $17.43 \mathrm{mg} \mathrm{g}^{-1} \mathrm{~min}^{1 / 2}$ ) for both concentrations, revealing that intra-particle diffusion was the main rate-controlling step. The third stage, the final equilibrium stage, was very slow and this was mainly ascribed to the low concentration left in solution. Increasing concentration from $120 \mathrm{mg} \mathrm{L}^{-1}$ to $200 \mathrm{mg} \mathrm{L}^{-1}$, both inter-particle diffusion and intra-particle diffusion were elevated, which suggested that increasing concentration favored transferring AO7 from bulk solution to $\mathrm{HAPC}_{\mathrm{HCl}+\mathrm{HF}}$ particle and to its inner surface.

The adsorption kinetic indicated excellent performance of AO7 adsorption by $\mathrm{HAPC}_{\mathrm{HCl}+\mathrm{HF}}$, which depending on unique properties of $\mathrm{HAPC}_{\mathrm{HCl}+\mathrm{HF}}$. Firstly, the highly porous structure of $\mathrm{HAPC}_{\mathrm{HCl}+\mathrm{HF}}$ made $\mathrm{AO} 7$ easy to reach the $\mathrm{HAPC}_{\mathrm{HCl}+\mathrm{HF}}$ surface through capillary effect (Cazetta et al., 2016). Secondly, the average pore diameter of $\mathrm{HAPC}_{\mathrm{HCl}+\mathrm{HF}}(4.87 \mathrm{~nm})$ was larger than $\mathrm{AO}$ molecule size $(1.36 \times 0.73 \times 0.23 \mathrm{~nm}$ in three-dimensional size $)$, facilitating the fast and accessible diffusion of AO7 into intra-particles (Hung-Lung et al., 2007).

\subsubsection{Adsorption isotherms}

The adsorption isotherms were investigated at temperatures ranging from $288 \mathrm{~K}$ to $308 \mathrm{~K}$. The data obtained were fitted by Langmuir (Eq. (7)) and Freundlich (Eq. (8)) adsorption isotherms models, respectively.

$\frac{\mathrm{C}_{\mathrm{e}}}{\mathrm{q}_{\mathrm{e}}}=\frac{1}{\mathrm{q}_{\mathrm{m}} \mathrm{b}}+\frac{\mathrm{C}_{\mathrm{e}}}{\mathrm{q}_{\mathrm{m}}}$

$\ln \mathrm{q}_{\mathrm{e}}=\ln \mathrm{K}_{\mathrm{F}}+\frac{1}{\mathrm{n}} \ln \mathrm{C}_{\mathrm{e}}$

where $C_{e}$ is the equilibrium dye concentration $\left(\mathrm{mg} \mathrm{L}^{-1}\right)$ in solution, $\mathrm{q}_{\mathrm{e}}$ is the amount adsorbed on adsorbent at equilibrium $\left(\mathrm{mg} \mathrm{g}^{-1}\right)$ and $\mathrm{q}_{\mathrm{m}}$ is maximum adsorption capacity determined by the number of reactive sites in an ideal monolayer system $\left(\mathrm{mg} \mathrm{g}^{-1}\right)$ and $\mathrm{b}(\mathrm{L}$ $\mathrm{mg}^{-1}$ ) is the Langmuir constants related to energy of adsorption, $\mathrm{K}_{\mathrm{F}}$ is the Freundlich constant related to the bonding energy, which can be defined as the adsorption or distribution coefficient and respects the adsorption capacity of adsorbents $\left(\mathrm{mg} \mathrm{g}^{-1}\right)$.

In addition, the essential characteristic of the Langmuir isotherm and the dimensionless constant $\mathrm{R}_{\mathrm{L}}$, could be expressed by the following equation:

$\mathrm{R}_{\mathrm{L}}=\frac{1}{1+\mathrm{bC}_{0}}$

where $C_{0}$ is the initial dye concentration, $m g L^{-1}$. $R_{L}$ shows the nature of adsorption mechanism. In general, an isotherm can be irreversible $\left(\mathrm{R}_{\mathrm{L}}=0\right)$, favorable $\left(0<\mathrm{R}_{\mathrm{L}}<1\right)$, linear $\left(\mathrm{R}_{\mathrm{L}}=1\right)$ or unfavorable $\left(R_{L}>1\right)$ (Hamzeh et al., 2012).

The adsorption isotherms were depicted in Table 4. It can be seen that the correlation coefficients of Langmuir adsorption isotherm were much higher than those of Freundlich adsorption isotherm, indicating a best fit between Langmuir adsorption isotherm and the experiment date. The values of $R_{L}(0.0016)$ implied that the adsorption process was favorable. In addition, the great $\mathrm{q}_{\mathrm{m}}\left(243.9-440.53 \mathrm{mg} \mathrm{g}^{-1}\right)$ was competitive with or higher than other carbon materials prepared from other precursor including fish waste (Liu et al., 2016), spent brewery grains (Hamzeh et al., 2012), brown macroalga (Kousha et al., 2012), sludge adsorbent and commercial activated carbon fibers (HsiuMei et al., 2009). Additionally, a high b value of 0.418-1.52 $\mathrm{L} \mathrm{mg}^{-1}$ suggested the strong adsorption of AO7 onto $\mathrm{HAPC}_{\mathrm{HCl}+\mathrm{HF}}$, which migh originate from $\pi-\pi$ stacking interaction (Ma et al., 2014).

As $\mathrm{AO} 7$ is an acid dye, the basic surface of $\mathrm{HAPC}_{\mathrm{HCl}+\mathrm{HF}}$ played important role on the adsorption. The natural pH of AO7 solutions ranged from 6.19 to 6.64 (Table S1) in the present study and the AO7 existed only as negative sulphonic-OH (Elizalde-Gonzalez and Hernandez-Montoya, 2009). Therefore, the electrostatic attraction between basic groups on $\mathrm{HAPC}_{\mathrm{HCl}+\mathrm{HF}}$ surface and $\mathrm{AO} 7$ molecule were the main adsorption forces. As we know that, the surface of carbon materials is positively charged when $\mathrm{pH}$ is lower than $\mathrm{pH}_{\mathrm{zpc}}$ and has the negative charges when $\mathrm{pH}$ is higher than $\mathrm{pH}_{\mathrm{zpc}}$. The $\mathrm{pH}_{\mathrm{zpc}}$ of $\mathrm{HAPC}_{\mathrm{HCl}+\mathrm{HF}}$ was measured to be 6.4 (Table 2), consequently, when $\mathrm{pH}$ was lower than $\mathrm{pH}_{\mathrm{zpc}}$, the surface positive charges of $\mathrm{HAPC}_{\mathrm{HCl}+\mathrm{HF}}$ contributed to the uptake of negative AO7. This result was also confirmed by the zeta potential analysis. Increasing concentration would lower solution $\mathrm{pH}$ and then favor surface positive change of $\mathrm{HAPC}_{\mathrm{HCl}+\mathrm{HF}}$, which may contribute to the

Table 4

Langmuir and Freundlich isotherm models for AO7 adsorption.

\begin{tabular}{|c|c|c|c|c|c|c|c|}
\hline \multirow[t]{2}{*}{ Temperature (K) } & \multicolumn{4}{|c|}{ Langmuir Parameters } & \multicolumn{3}{|c|}{ Freundlich Parameters } \\
\hline & $\mathrm{q}_{\mathrm{m}}\left(\mathrm{mg} \mathrm{g}^{-1}\right)$ & $\mathrm{b}\left(\mathrm{L} \mathrm{mg}^{-1}\right)$ & $\mathrm{R}_{\mathrm{L}}$ & $\mathrm{R}^{2}$ & $\mathrm{~K}_{\mathrm{F}}\left(\mathrm{L} \mathrm{mg}^{-1}\right)$ & $1 / \mathrm{n}$ & $\mathrm{R}^{2}$ \\
\hline 288 & 384.62 & 1.07 & 0.0016 & 0.9929 & 114.15 & 0.2279 & 0.8470 \\
\hline 298 & 440.53 & 1.52 & 0.0016 & 0.9966 & 239.85 & 0.1306 & 0.9491 \\
\hline 308 & 243.90 & 0.418 & 0.0016 & 0.9787 & 212.87 & 0.0643 & 0.2316 \\
\hline
\end{tabular}


excellent $\mathrm{AO} 7$ removal efficiency by $\mathrm{HAPC}_{\mathrm{HCl}+\mathrm{HF}}$ even at high concentration. In addition, the graphitic structures doped with heteroatoms of $\mathrm{N}$ and $\mathrm{S}$ of $\mathrm{HAPC}_{\mathrm{HCl}+\mathrm{HF}}$ also promoted the adsorption. The N (3.04) and S (2.58) doped into graphitic structure had large electronegativity with respect to $C$ atoms (2.55) would improve positive charge density on adjacent $C$ atoms and resulted in enhanced electrostatic attraction between $\mathrm{AO} 7$ molecular and $\mathrm{HAPC}_{\mathrm{HCl}+\mathrm{HF}}$ regardless of initial concentration (Yang et al., 2012).

\section{Conclusions}

A naturally $\mathrm{N}$ and S-doped porous carbon adsorbent $\left(\mathrm{HAPC}_{\mathrm{HCl}+\mathrm{HF}}\right)$ was prepared by hydrothermal carbonization combined with chemical activation of sewage sludge for the first time. The prepared carbon adsorbent exhibited unique properties including the presence of substantial amount of mesopores, highly graphitized degree and heteroatoms doping. The adsorption of AO7 onto the carbon followed pseudo second-order kinetics and well obeyed Langmuir isotherm model with ultrahigh the maximum adsorption capacity of $440.53 \mathrm{mg} \mathrm{g}^{-1}$ at $25^{\circ} \mathrm{C}$. The $\pi-\pi$ stacking interaction and electrostatic attraction between $\mathrm{AO} 7$ and the adsorbent, as well as excellent porous properties were mainly contributed to the high adsorption capacity. This study provided a low cost and simple technical route to prepare highly efficient carbon adsorbent towards azo dye contaminated wastewater treatment.

\section{Acknowledgements}

The authors gratefully acknowledge financial support for Zhengang Liu from the "100 Talents" Program of the Chinese Academy of Sciences (Project No. Y5N41I1C01).

\section{Appendix A. Supplementary data}

Supplementary data related to this article can be found at http:// dx.doi.org/10.1016/j.jenvman.2017.03.082.

\section{References}

Cazetta, A.L., Martins, A.C., Pezoti, O., Bedin, K.C., Beltrame, K.K., Asefa, T. Almeida, V.C., 2016. Synthesis and application of N-S-doped mesoporous carbon obtained from nanocasting method using bone char as heteroatom precursor and template. Chem. Eng. J. 300, 54-63.

Elizalde-Gonzalez, M.P. Hernandez-Montoya, V., 2009. Removal of acid orange 7 by guava seed carbon: a four parameter optimization study. J. Hazard. Mater. 168, $515-522$.

Escala, M., Zumbühl, T., Koller, C., Junge, R., Krebs, R., 2013. Hydrothermal carbonization as an energy-efficient alternative to established drying technologies for sewage sludge: a feasibility study on a laboratory scale. Energy Fuels 27, $454-460$.

Gai, C., Guo, Y., Peng, N., Liu, T., Liu, Z, 2016. N-Doped biochar derived from cohydrothermal carbonization of rice husk and Chlorella pyrenoidosa for enhancing copper ion adsorption. RSC Adv. 6, 53713-53722.

Goertzen, S.L., Thériault, K.D., Oickle, A.M., Tarasuk, A.C., Andreas, H.A., 2010 Standardization of the Boehm titration. Part I. CO2 expulsion and endpoint determination. Carbon 48, 1252-1261.

Hamzeh, Y., Ashori, A., Azadeh, E., Abdulkhani, A., 2012. Removal of Acid Orange 7 and Remazol Black 5 reactive dyes from aqueous solutions using a novel biosorbent. Mater. Sci. Eng. C 32, 1394-1400.

Hsiu-Mei, C., Ting-Chien, C., San-De, P., Chiang, H.-L., 2009. Adsorption characteristics of Orange II and Chrysophenine on sludge adsorbent and activated carbon fibers. J. Hazard. Mater. 161, 1384-1390.

Hung-Lung, C., Kuo-Hsiung, L., Shih-Yu, C., Ching-Guan, C., San-De, P., 2007. Dye adsorption on biosolid adsorbents and commercially activated carbon. Dye Pigm. 75, 52-59.
Jain, A., Balasubramanian, R., Srinivasan, M.P., 2016. Hydrothermal conversion of biomass waste to activated carbon with high porosity: a review. Chem. Eng. J. 283, 789-805.

Jaria, G., Silva, C.P., Ferreira, C.I.A., Otero, M., Calisto, V., 2017. Sludge from paper mill effluent treatment as raw material to produce carbon adsorbents: an alternative waste management strategy. J. Environ. Manag. 188, 203-211.

Kacan, E., 2016. Optimum BET surface areas for activated carbon produced from textile sewage sludges and its application as dye removal. J. Environ. Manag. $166,116-123$.

Kousha, M., Daneshvar, E., Sohrabi, M.S., Jokar, M., Bhatnagar, A., 2012. Adsorption of acid orange II dye by raw and chemically modified brown macroalga Stoechospermum marginatum. Chem. Eng. J. 192, 67-76.

Laurent, J., Casellas, M., Carrère, H., Dagot, C., 2011. Effects of thermal hydrolysis on activated sludge solubilization, surface properties and heavy metals biosorption. Chem. Eng. J. 166, 841-849.

Li, J., Hou, M., Chen, Y., Cen, W., Chu, Y., Yin, S., 2017. Enhanced $\mathrm{CO}_{2}$ capture on graphene via N, S dual-doping. Appl. Surf. Sci. 399, 420-425.

Lin, Q.H., Cheng, H., Chen, G.Y., 2012. Preparation and characterization of carbonaceous adsorbents from sewage sludge using a pilot-scale microwave heating equipment. J. Anal. Appl. Pyrolysis 93, 113-119.

Liu, Z., Zhang, F.-S., Wu, J., 2010. Characterization and application of chars produced from pinewood pyrolysis and hydrothermal treatment. Fuel 89, 510-514.

Liu, Z., Zhang, F., Liu, T., Peng, N., Gai, C., 2016. Removal of azo dye by a highly graphitized and heteroatom doped carbon derived from fish waste: adsorption equilibrium and kinetics. J. Environ. Manag. 182, 446-454.

Ma, T., Chang, P.R., Zheng, P., Zhao, F., Ma, X., 2014. Fabrication of ultra-light graphene-based gels and their adsorption of methylene blue. Chem. Eng. J. 240, 595-600.

Peccia, J., Westerhoff, P., 2015. We should expect more out of our sewage sludge Environ. Sci. Technol, 49, 8271-8276.

Plank, J., Hirsch, C., 2007. Impact of zeta potential of early cement hydration phases on superplasticizer adsorption. Cem. Concr. Res. 37, 537-542.

Qian, W., Sun, F., Xu, Y., Qiu, L., Liu, C., Wang, S., Yan, F., 2014. Human hair-derived carbon flakes for electrochemical supercapacitors. Energy Environ. Sci. 7 , 379-386.

Qiu, B., Pan, C., Qian, W., Peng, Y., Qiu, L., Yan, F., 2013. Nitrogen-doped mesoporous carbons originated from ionic liquids as electrode materials for supercapacitors. J. Mater. Chem. A 1, 6373-6378.

Rio, S., Faur-Brasquet, C., Le Coq, L., Le Cloirec, P., 2005. Structure characterization and adsorption properties of pyrolyzed sewage sludge. Environ. Sci. Technol. 39 4249-4257.

Silva, J.P., Sousa, S., Gonçalves, I., Porter, J.J., Ferreira-Dias, S., 2004. Modelling adsorption of acid orange 7 dye in aqueous solutions to spent brewery grains. Sep. Purif. Technol. 40, 163-170.

Silva, T.L., Ronix, A., Pezoti, O., Souza, L.S., Leandro, P.K.T., Bedin, K.C., Beltrame, K.K. Cazetta, A.L., Almeida, V.C., 2016. Mesoporous activated carbon from industrial laundry sewage sludge: adsorption studies of reactive dye Remazol Brilliant Blue R. Chem. Eng. J. 303, 467-476.

Smith, K.M., Fowler, G.D., Pullket, S., Graham, N.J.D., 2009. Sewage sludge-based adsorbents: a review of their production, properties and use in water treatment applications. Water Res. 43, 2569-2594.

Tian, Y., Zhang, J., Zuo, W., Chen, L., Cui, Y., Tan, T., 2013. Nitrogen conversion in relation to $\mathrm{NH}_{3}$ and $\mathrm{HCN}$ during microwave pyrolysis of sewage sludge. Environ. Sci. Technol. 47, 3498-3505.

Wang, Z. Li, Q. Lin, Z., Whiddon, R., Oiu, K., Kuang, M., Cen, K., 2016. Transformation of nitrogen and sulphur impurities during hydrothermal upgrading of low quality coals. Fuel 164, 254-261.

Yang, K., Zhu, Y., Shan, R., Shao, Y., Tian, C., 2017. Heavy metals in sludge during anaerobic sanitary landfill: speciation transformation and phytotoxicity. J. Environ. Manag. 189, 58-66.

Yang, Z., Yao, Z., Li, G., Fang, G., Nie, H., Liu, Z., Zhou, X., Chen, X.a., Huang, S., 2012. Sulfur-doped graphene as an efficient metal-free cathode catalyst for oxygen reduction. ACS Nano 6, 205-211.

Ye, D., Wang, L., Zhang, R., Liu, B., Wang, Y., Kong, J., 2015. Facile preparation of Ndoped mesocellular graphene foam from sludge flocs for highly efficient oxygen reduction reaction. J. Mater. Chem. A 3, 15171-15176.

Yuan, S.-J., Dai, X.-H., 2015. Heteroatom-doped porous carbon derived from "all-inone" precursor sewage sludge for electrochemical energy storage. RSC Adv. 5, $45827-45835$.

Zhang, D., Chen, Y., Zhao, Y., Zhu, X., 2010. New sludge pretreatment method to improve methane production in waste activated sludge digestion. Environ. Sci. Technol. 44, 4802-4808.

Zhang, F.-S., Nriagu, J.O., Itoh, H., 2005. Mercury removal from water using activated carbons derived from organic sewage sludge. Water Res. 39, 389-395.

Zou, J., Dai, Y., Wang, X., Ren, Z., Tian, C., Pan, K., Li, S., Abuobeidah, M., Fu, H., 2013. Structure and adsorption properties of sewage sludge-derived carbon with removal of inorganic impurities and high porosity. Bioresour. Technol. 142 209-217. 